\title{
ARTE, CULTURA E EDUCAÇÃO: CONSTRUINDO CONHECIMENTO EM ESPAÇOS ARTÍSTICO-CULTURAIS FORA DA ESCOLA
}

\section{Gladis Falavigna ${ }^{1}$}

O referido curso de extensão 40/horas, módulo 1, foi organizado pela Pró-Reitoria de Extensão da Universidade Estadual do Rio Grande do Sul, UERGS e ocorreu em outubro de 2003 em Porto Alegre, RS, Brasil tendo como parceiros diferentes instituições culturais da comunidade local. O objetivo geral do curso foi proporcionar aos professores e interessados em geral, subsídios teóricos e atividades práticas relacionando Arte, Cultura, Educação e Novas Tecnologias de Comunicação e Informação - NTIC com museus e centros artístico-culturais como formas alternativas de construção do conhecimento fora da escola.

Os objetivos específicos visaram conhecer o Museu de Arte do RS-MARGS, Atelier Livre da Prefeitura de Porto Alegre, Centro Municipal de Cultura-CMC, Memorial do RS, Museu de Ciência e Tecnologia - MCT/PUCRS e Santander Cultural; analisar metodologias de projetos; elaborar um projeto; analisar o significado de Criatividade e as fases do processo criativo; realizar leituras e releituras das atividades experienciadas; dialogar com um artista em seu local de trabalho; utilizar diferentes recursos, tintas, pincéis, lápis, giz, Microcomputador, videoconferência.

Videoconferência de abertura do curso -

Reitor da UERGS

Dr.Nelson Boeira

Unidades de Ensino conectadas:

Porto Alegre, Alegrete, Bagé, Cruz Alta, Vacaria

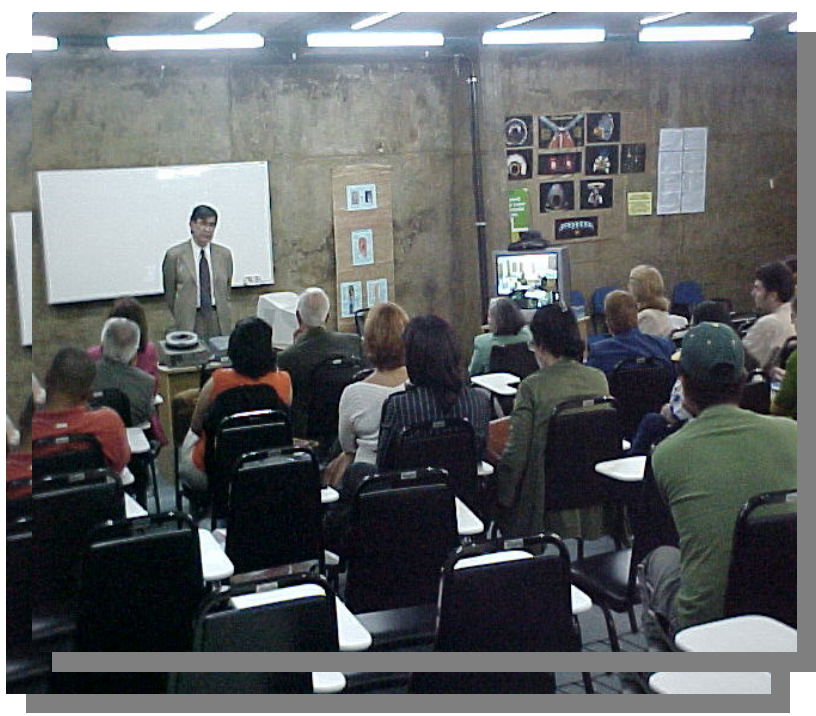

${ }^{1}$ Profa. Dra. em Educação, Assessora da Pró-Reitoria de Ensino da UERGS - Profa dos cursos de Pós-Graduação da FIJO/PUCRS. 
Casa de Cultura Mário Quintana

Arte, Cultura e Educação

construindo conhecimento

em espaços artístico-culturais

fora da escola

Apresentação da Casa de Cultura Mario Quintana - Dr. Sérgio Napp

- Histórico e evolução

- Captação de recursos

- Projetos

- Editais

- Exposições

Apresentação do MARGS Dr. Paulo Amaral

A evolução do MARGS como instituição cultural: uma visão contemporânea Exposições - Bienal do Mercosul

Projetos Pedagógicos: Núcleo de Extensão
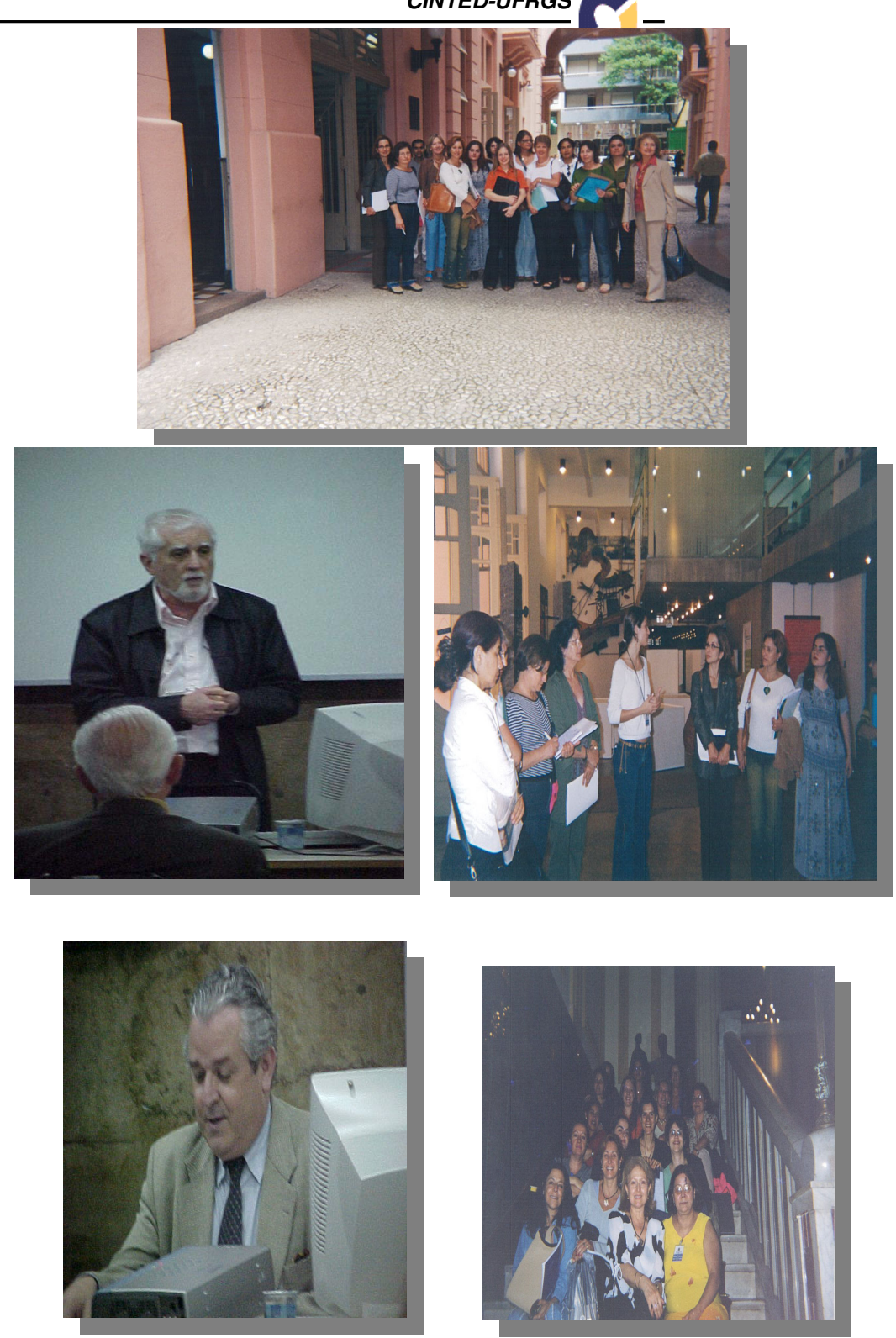

A presentação do Centro Municial de Cultura Andrea Rotunno

- Projetos

- Editais

- Recursos

- Cursos

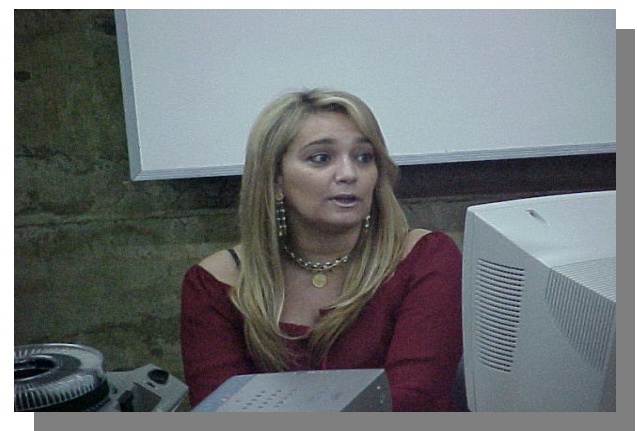


O Atelier Livre da Prefeitura de POA/RS

Profa. Daysi Viola

Oficinas, cursos, editais, projetos, exposições, seminários

Atelier: Oficina de Pintura
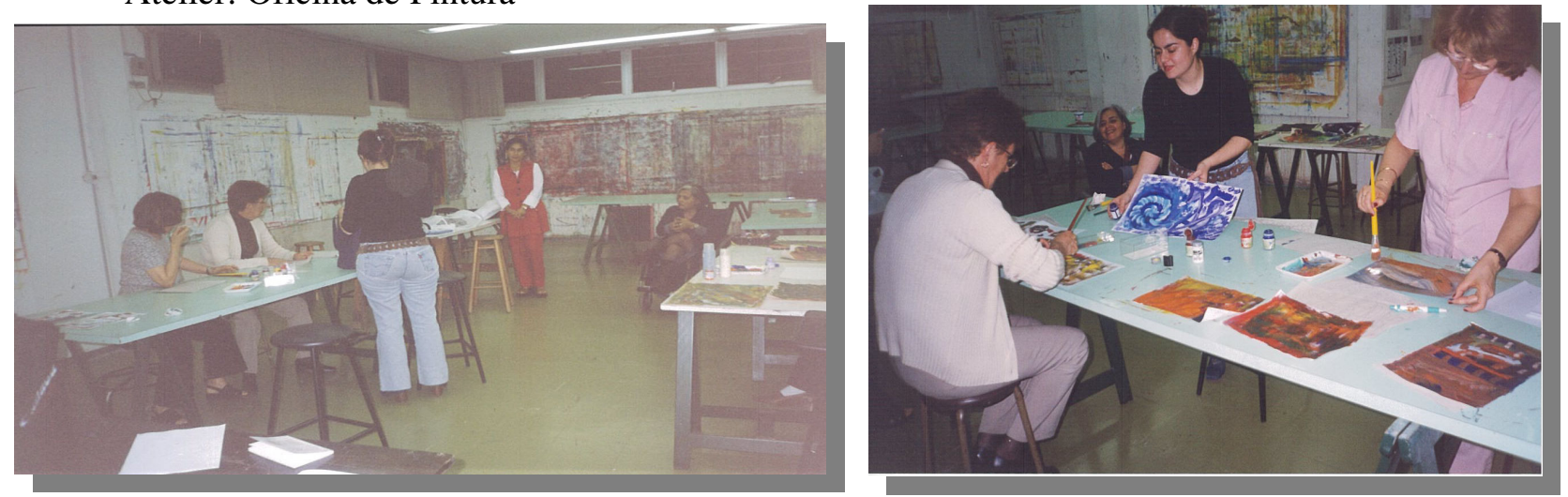

Atelier: Oficina de Pintura

Atelier: Oficina de Gravura em Metal

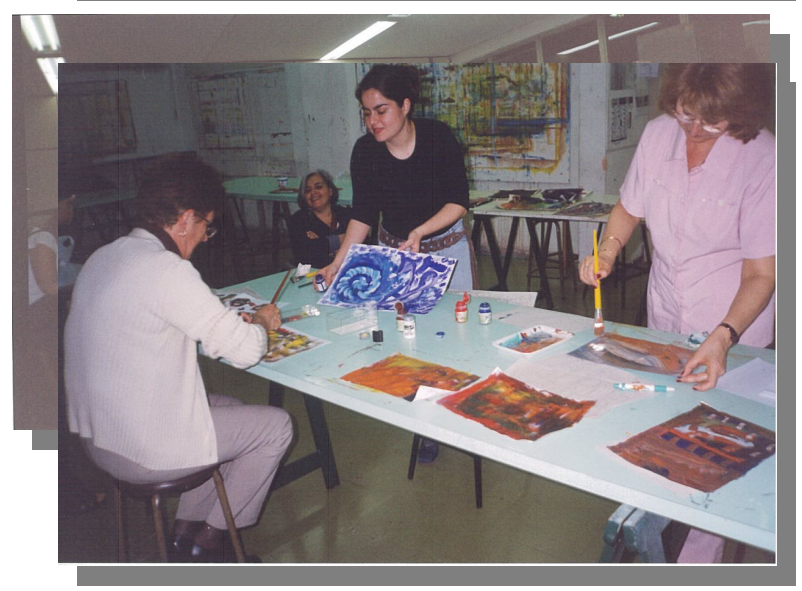

Museu Hipólito da Costa Dr. Antônio Henriques A Comunicação no Rio Grande do Sul: histórico, evolução e atualidade.

Exposição: Idéias que mudaram este país
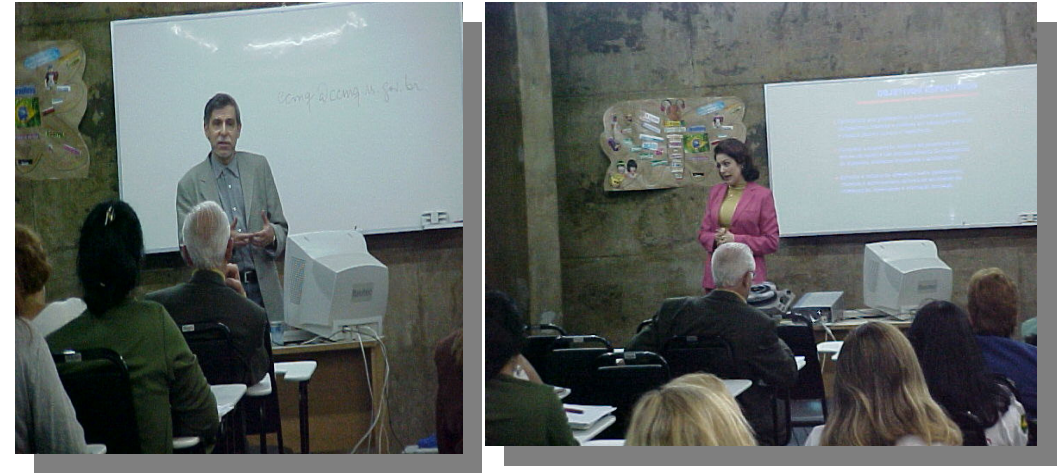
Propaganda Brasileira

Orquestra Sinfônica de Porto AlegreProjeto: Educação Musical Apl;icada Profa. Dra. Liane Hentschke

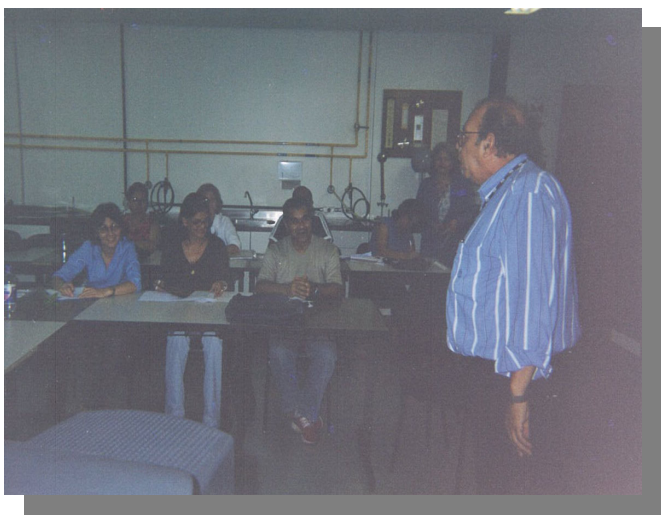

Museu de Ciências e Tecnologia / MCT/PUCRS Oficina:

Confecção de Material Didático.

\section{MCT/PUCRS}

Serviços à Comunidade: exposições interativas, pesquisa, atendimento e orientação a professores

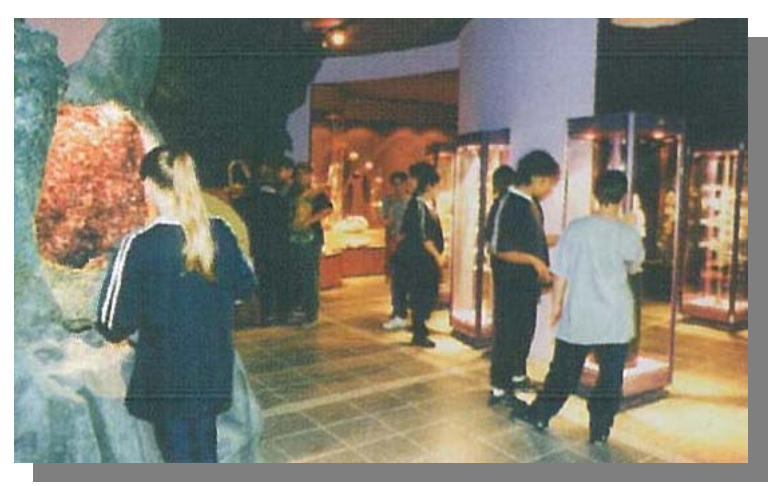
e alunos, elaboração e desenvolvimento de cursos para os três níveis de ensino, museu itinerante, capacitação e aperfeiçoamento de profissionais. 
Santander Cultural:

A evolução histórica dos museus Projetos Pedagógicos

Exposições

Bienal do Mercosul
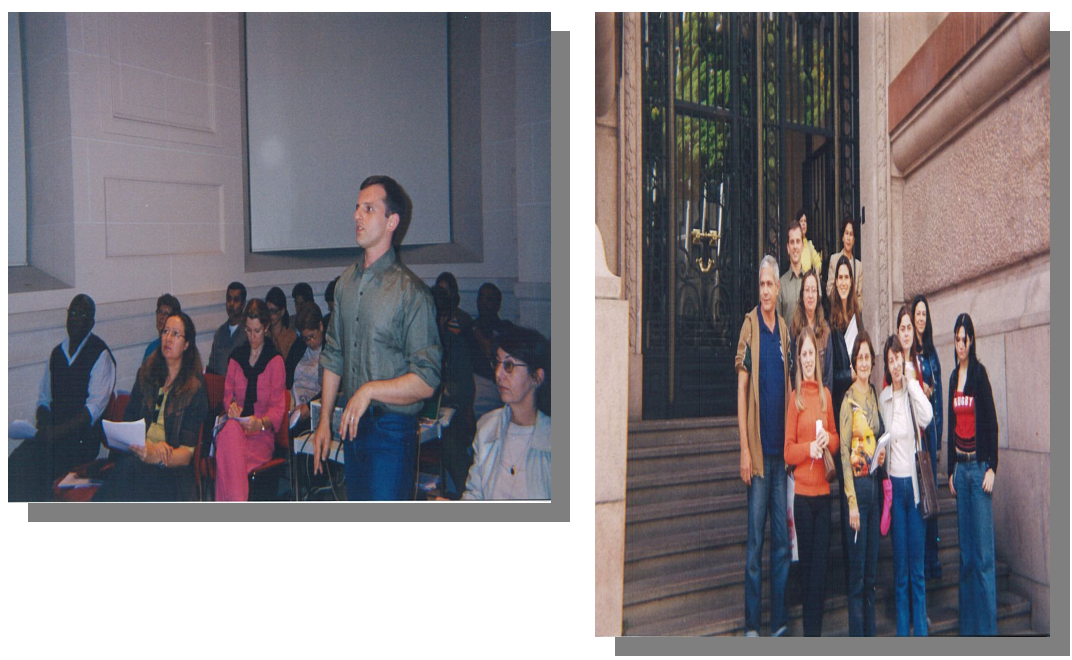

Memorial do RS

Dr. José Bachieri Duarte

Exposições

Cursos

Seminários, Projetos

Prof. Decio Andriott

PUCRS e UFSC

A Historia e a Arte do RS
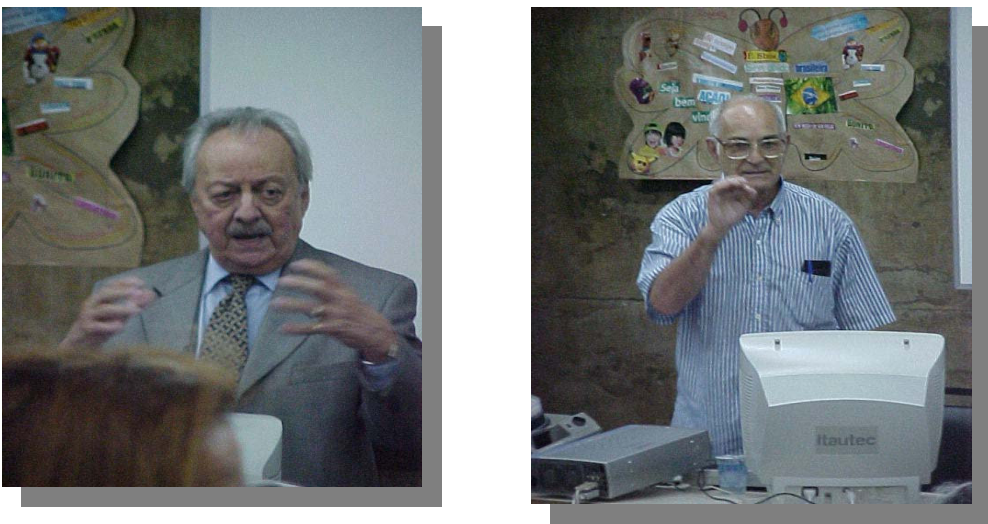

A justificativa do projeto destaca as possibilidades de construção do conhecimento fora da escola, a partir de diferentes atividades culturais existentes em POA ou em outras comunidades, ampliando o conceito de sala de aula, permitindo o contato direto com o artista e sua produção, colaborando com o desenvolvimento local, relacionando arte, cultura, educação e proporcionando aprendizagem colaborativa com diferentes tecnologias de informação e comunicação.

Os temas tratados durante o curso debateram questões relativas à Função social dos Museus, Projetos pedagógicos, Arte-educação, Gravura em Metal, Pintura, Xilogravura, Da Visita Turística à Visita da Descoberta, A Evolução do MARGS como Instituição Cultural: uma visão contemporânea, A função sócio-histórica dos museus, Criatividade, Releituras

Museu de Ciências e Tecnologia, Videoconferência e Educação a Distância, EAD, Projeto de Educação Musical Aplicada, POEMA da Orquestra Sinfônica de Porto 
Alegre, OSPA, Metodologia de Projetos, Captação de Recursos, Arte-Educação,.A História e a Arte do RS.

As iniciativas de captação de recursos humanos para a realização deste projeto, permitiram a constituição de uma equipe interinstitucional, de diferentes áreas, bastante motivada e colaborativa, possibilitando a concretização do curso.

Cabe neste momento um agradecimento especial ao Dr. Roque Jacob, Secretário de Estado da Cultura do RS, às Coordenadorias Regionais da Secretaria de Educação do Estado do Rio Grande do Sul, ao Dr. Paulo César Brasil do Amaral, Diretor do Museu de Arte do Rio Grande do Sul - MARGS, Dr. Sérgio Napp, Diretor da Casa de Cultura Mário Quintana, Dr. Jeter Jorge Bertoletti, Diretor do Museu de Ciências e Tecnologia da Pontifícia Universidade Católica do Rio Grande do Sul, MCT/PUCRS, Profa. Dra. Marilú Medeiros, Diretora de Educação a Distância da PUCRS, Profa. Dra. Magda Bercht do Instituto de Informática da UFRGS, Dr. Antônio Renato Henriques, Diretor do Museu de Comunicação Social José Hipólito da Costa, Dr. José Bachieri Duarte, Diretor do Memorial do RS, Profa. Nara Nunes, Diretora do Museu Júlio de Castilhos, Profa. Andrea Rotunno, Diretora do Centro Municipal de Cultura de Porto Alegre, Profa. Dayse Viola, Diretora do Atelier Livre da Prefeitura de Porto Alegre, Profa. Dra. Liane Hentschke do POEMA/OSPA, Prof. Wilson Cavalcante do Atelier Livre da Prefeitrua de Porto Alegre - Oficina de Gravura em Metal, Profa. Vera Lúcia Machado da Rosa do Núcleo de Estensão do MARGS, Prof. Nei Vargas, Coordenador de Ações Educativas do Santander Cultural e Prof. Décio Andriotti dos cursos de Extensão da PUCRS e UFSC.

A Pró-Reitoria de Extensão - PROEX da Universidade Estadual do Rio Grande do Sul - UERGS promoveu e organizou o referido curso coordenado por Gladis Falavigna, Profa. Dra. da Pró-Reitoria de Ensino da mesma universidade.

As atividades propostas pelo curso ocorreram nos auditórios e espaços artísticoculturais próprios das diferentes instituições parceiras.

Casa de Cultura Mário Quintana Observação, palestra e debate

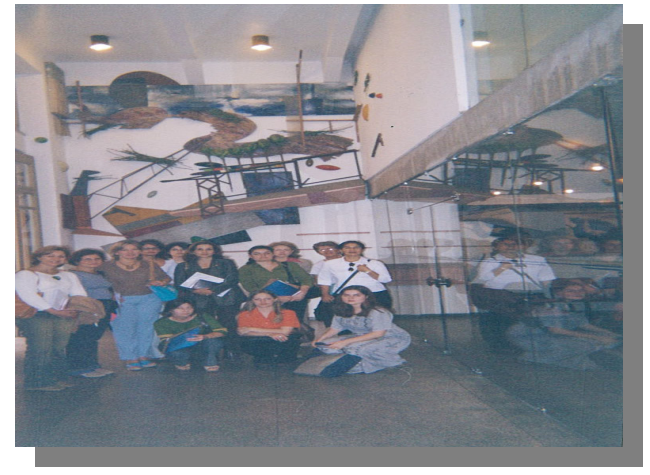

V. 2 № 1, Março, 2004 
O perfil dos 39 inscritos no curso de extensão, analisado mediante a ficha de inscrição, demonstra um interesse maior de profissionais oriundos da área da educação seguidos de estudantes pré-universitários, cientista social, coronel do exército aposentado e guia turístico

\section{CONCLUSÃO}

As avaliações individuais e em grupo, realizadas por escrito e oralmente ao final do curso, permitem afirmar que os resultados obtidos alcançaram os objetivos propostos.

As percepções dos participantes foram positivas proporcionando integração e motivação entre os participantes, despertando interesse, conhecimento, crescimento cultural originando novos projetos como Projeto Programa Permanente sobre Arte, Educação e Cultura tendo por objetivo geral proporcionar aos professores e interessados em geral um grupo de apoio permanente, especializado na organização de cursos, eventos e projetos artístico-culturais com atividades apoiadas nas novas tecnologias de informação e comunicação, Curso de Especialização - Arte-Educação, Curso de Extensão - Guia Turístico, Curso de Extensão - Mediadores e Visitas Orientadas, Curso de Extensão -Segurança no Trânsito, Organização e criação do Centro de Cultura Panambi - RS, Extensão do Projeto Poema em outras regiões do RS, nova edição do Curso de Extensão- Arte , Cultura e Educação, Módulo 1, Curso de Extensão - Arte, Cultura e Educação, Módulo 2 e a integração de outras áreas como dança, literatura, teatro, cinema, fotografia, televisão e propaganda.

\section{REFERÊNCIAS BIBLIOGRÁFICAS}

ASSMANN, H. Metáforas novas para reencantar a educação: epistemologia e didática. Piracicaba: Unimep, 1998.

CANÁRIO, Rui. Textos de João Barroso. Inovação e Projecto Educativo de Escola. Lisboa: Educa-Organizações, 1992.

GANDIN, Danilo. Planejamento como prática Educativa. 9. ed.. São Paulo: Edições Loyola, 1997.

GIL, Antonio Carlos. Como Elaborar Projetos de Pesquisa. 4. ed. São Paulo: Atlas, 2002.

GIMENO, José Sacristán. La educación que tenemos, la educación que queremos. In: La educación en el siglo XXI. Los retos del futuro inmediato. Barcelona: Graó, 1999. 
LIBEDINSKY, Marta. Los Museos y las Escuelas: de la visita turística a la visita de descubrimiento. In: Tecnología educativa: política, historias, propuestas. Buenos Aires: Paidós, 1995.

MORIN, E. Os sete saberes necessários à educação do futuro. São Paulo: Cortez. Brasília, DF: UNESCO, 2000.

OSTROWER, F. Criatividade e processos de criação. Petrópolis: Vozes, 1983.

PETERS, Otto. Didática do ensino a distância. São Leopoldo: UNISINOS, 2001.

REDIN, Maria Martins. Entrando pela janela: o encantamento do aluno pela escola. Porto Alegre: Mediação, 2002.

ZABALZA, Miguel A. Qualidade em educação infantil. (trad. Beatriz Affonso Neves. Porto Alegre: ArtMed, 1998. 